PAPER • Full original article online Free

level competitive behavior participants of sports activity and Teacher districts of Baghdad Education Directorate, in basketball championship Ramadan

*Naseer Khudhair Abbas \& Saad Khames Radhi

Directorate of Baghdad Education Karkh III, Ministry of Education, Baghdad, Iraq Naseeraltamemi@gmail.com

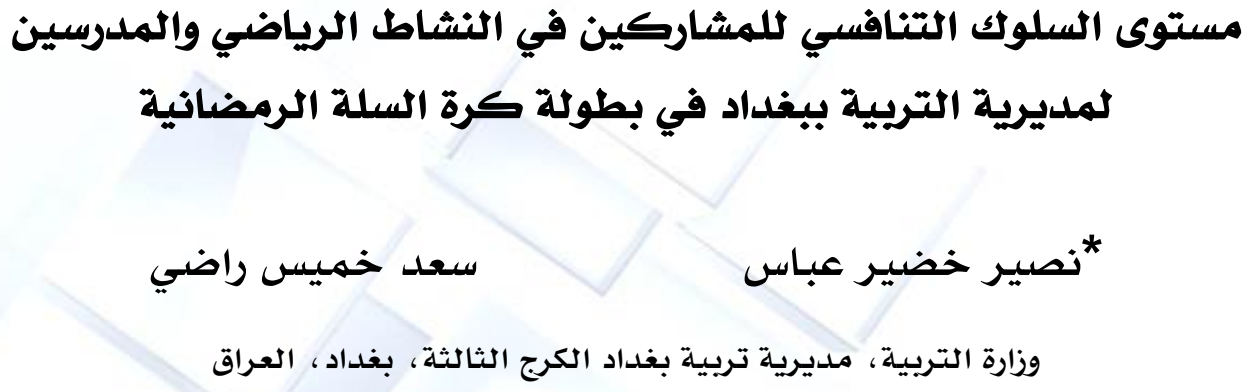

Naseeraltamemi@gmail.com

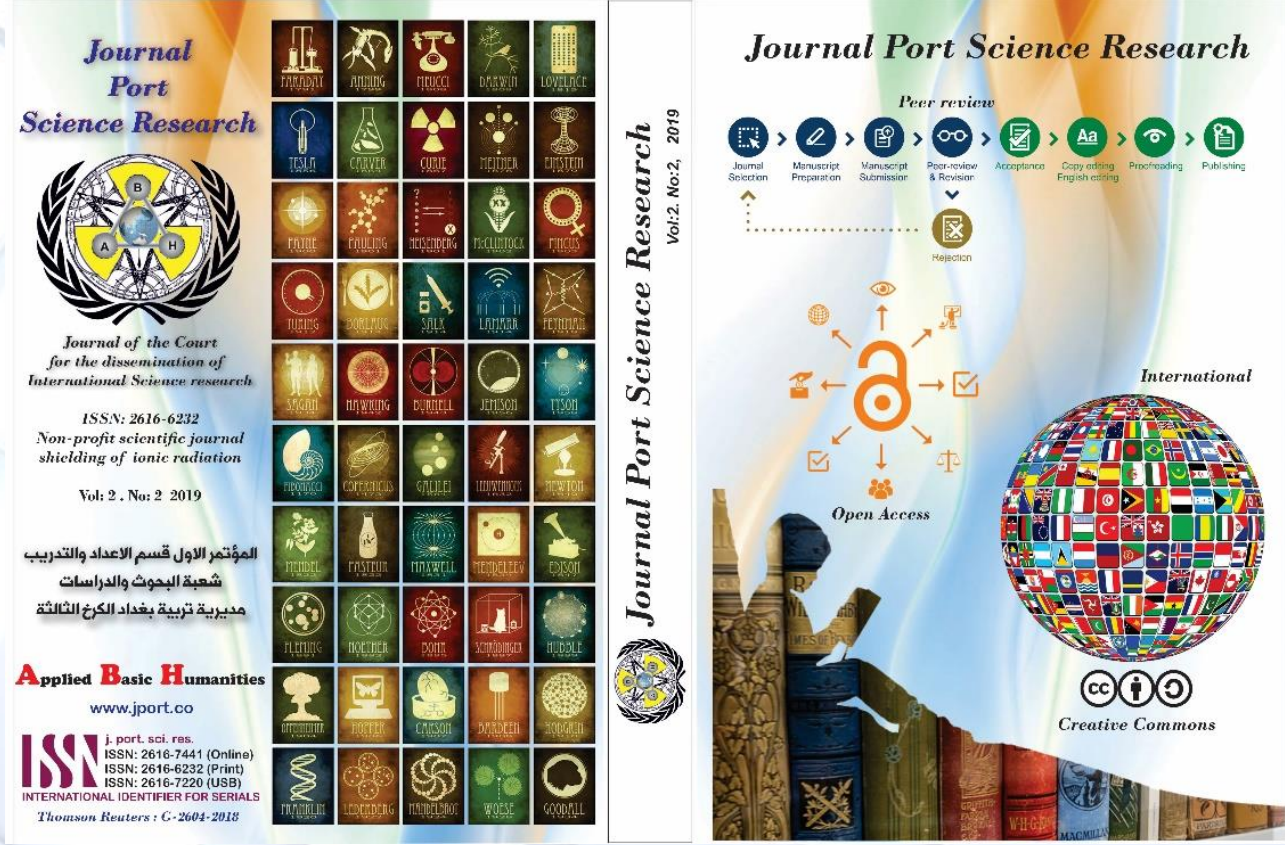

View for up https://jport.co

To cite this article: Published 2019 • (C) 2019 Bryant University United States of America Publishing Ltd. 
Ministry of Education Iraqi Directorate of Education Baghdad Karkh III

First Conference Department of Preparation and Training Division of Research and Studies

وزارة التربية العراقية ملديرية تريية بغلاد الكرخ الثالثة المؤتمر الاول قسم الاعلداد والتلدريب ثعبة البحوث واللدراسات

\title{
level competitive behavior participants of sports activity and Teacher districts of Baghdad Education Directorate, in basketball championship Ramadan
}

\author{
*Naseer Khudhair Abbas \\ $\&$ \\ Saad Khames Radhi \\ Directorate of Baghdad Education Karkh III, Ministry of Education, Baghdad, Iraq
}

Naseeraltamemi@gmail.com

\begin{abstract}
Aimed to identify the level of competitive behavior among the participants of the sections of sports and school activity of Baghdad's education in the championship Ramadan basketball in 2018, and to achieve the study was conducted on a sample of (72) technical supervisors and a teacher of sports education. the researchers used the descriptive method. the questionnaire was distributed to the participants and the statistical bag was used to analyze the results. the results showed that the degree of competitive behavior in the sample was significant with a percentage of response to $(73.6 \%)$. there was also no significant difference in the level of competitive behavior between technical supervisors and physical education teachers.
\end{abstract}

Keywords: competitive behavior, basketball, technical supervisors, physical education teachers.

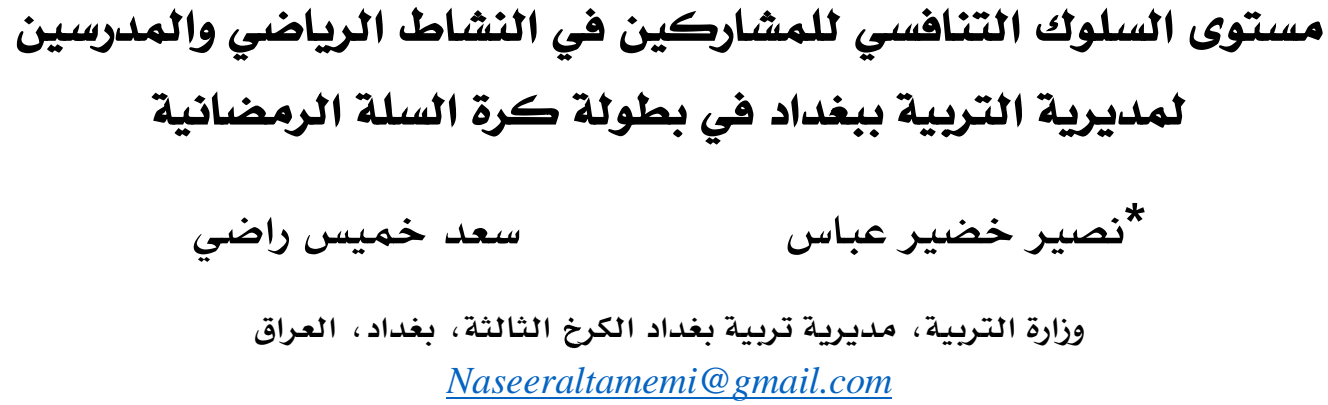

المستخلص التعرف على مستوى السلوك التنافسي لدى مشتركي أقسام النشاط الرياضي والمدرسي

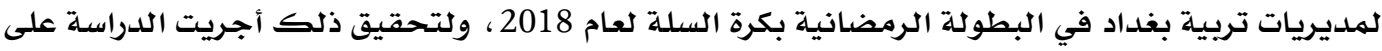

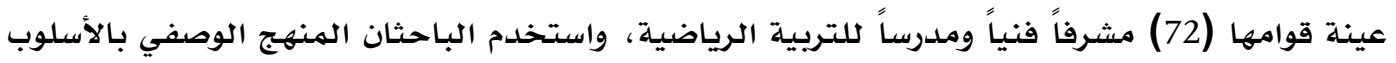

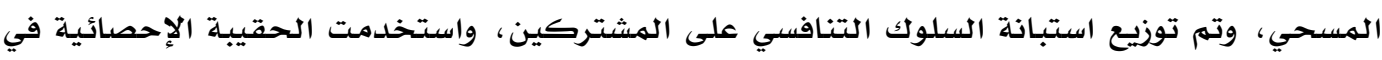

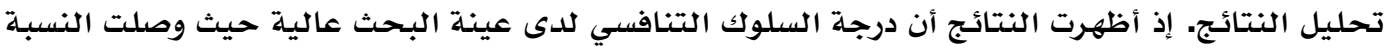

المئوية لكلاستجابة إلى (6,73٪) ، كذلك عدم وجود فروق ذات دلالة إحصائية في مستوى السلوك

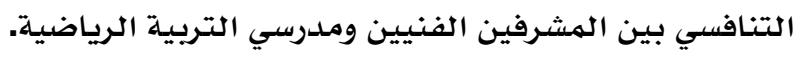

الكلمات اللاللة: السلوكك التنافسي، كرة السلة، الهشرفين الفنيين، معلهسي التربية البلسنية.

Abbas, N. Radhi, S. (2019). level competitive behavior participants of sports activity and Teacher districts of Baghdad Education Directorate, in basketball championship Ramadan. Journal Port Science Research, 2(2), 305-316. 


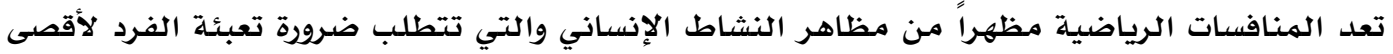

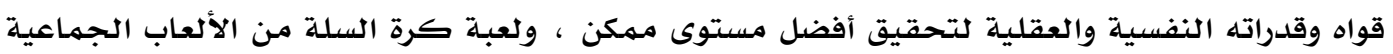

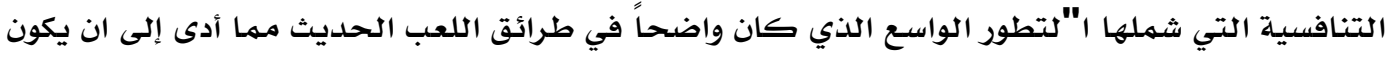

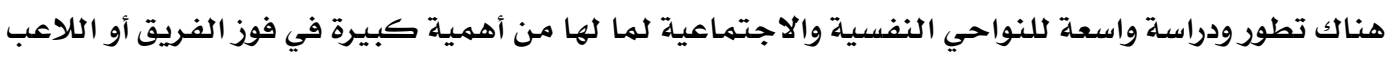

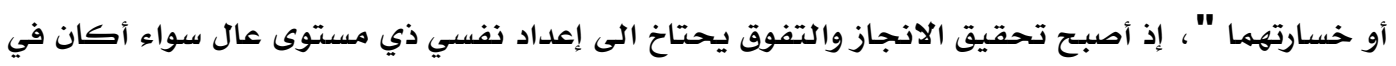

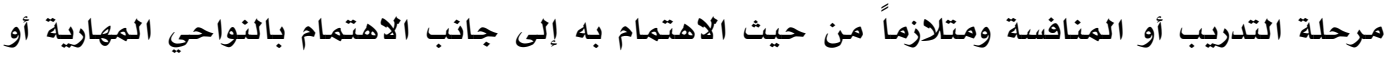

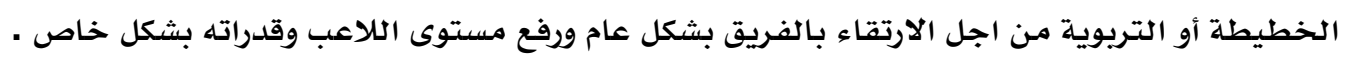

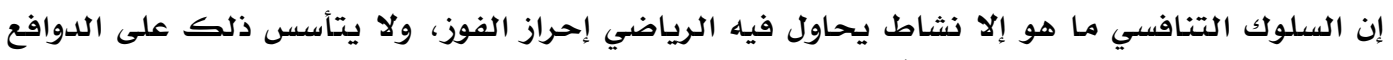

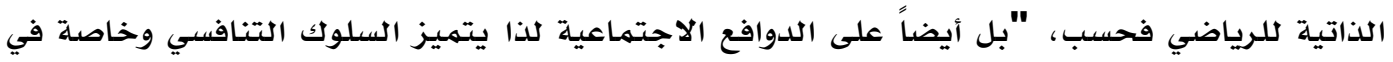

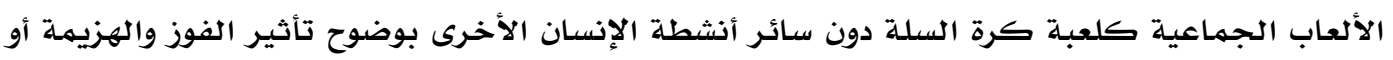

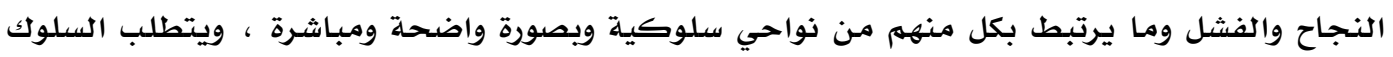

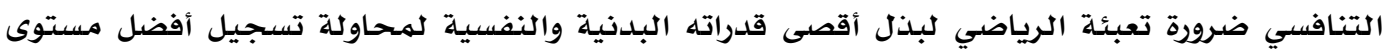

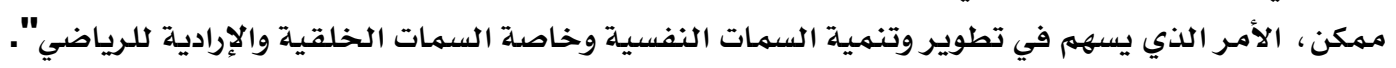

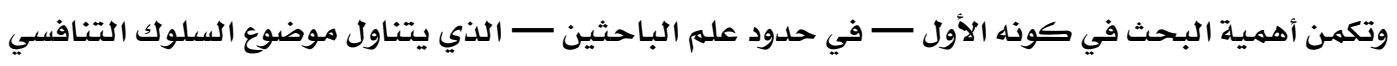

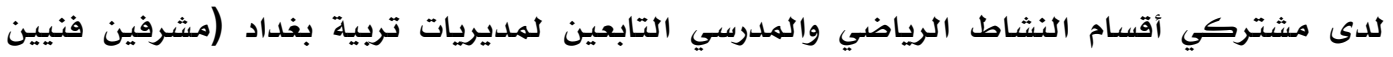

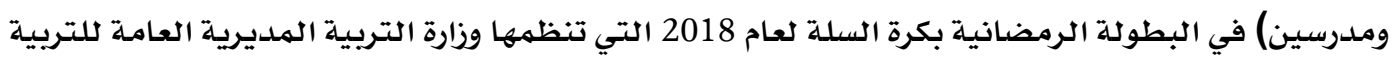

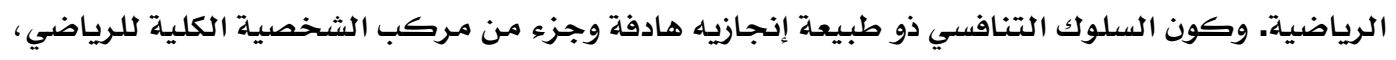

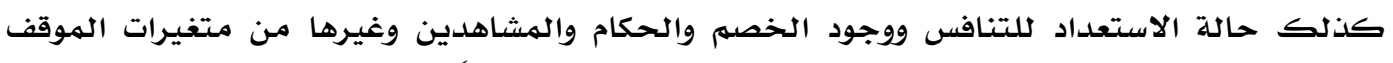

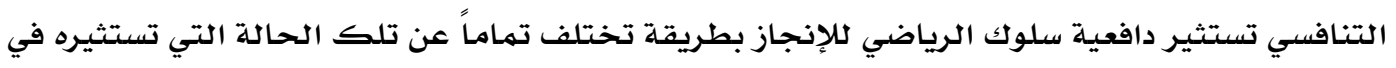

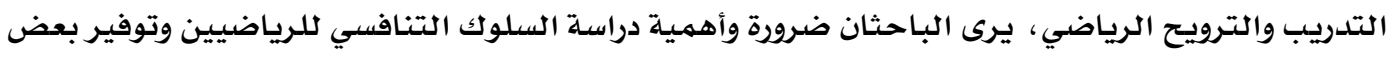

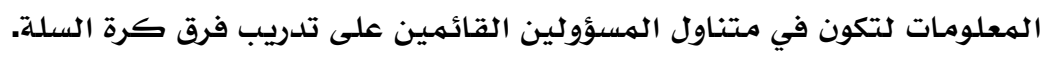

\section{مشكلة البحث}

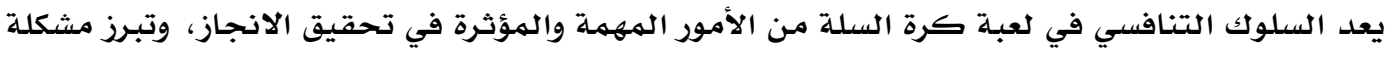

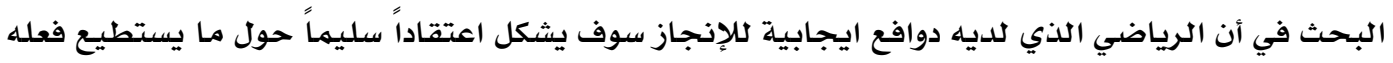

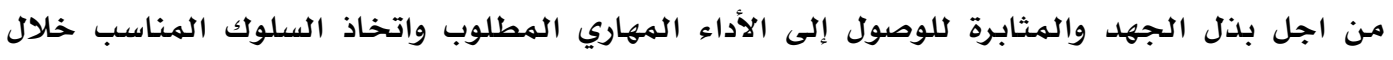

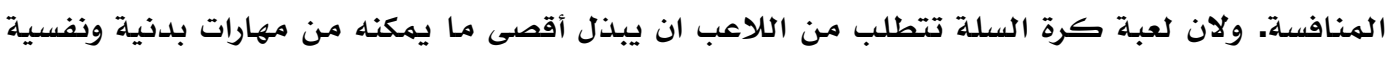

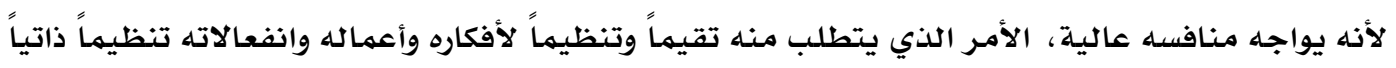

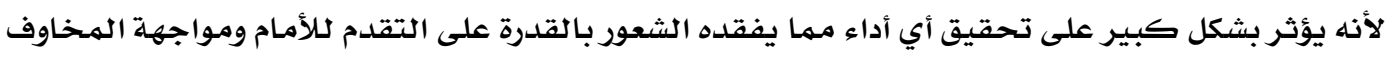

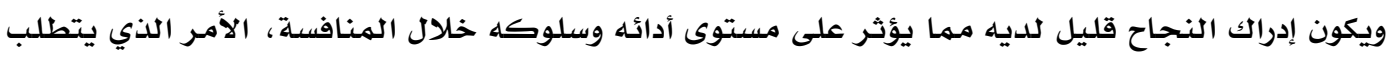

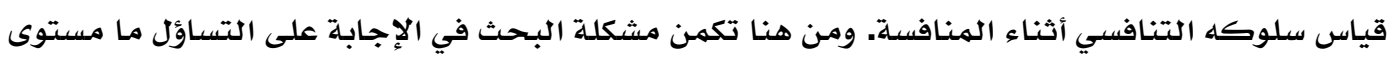

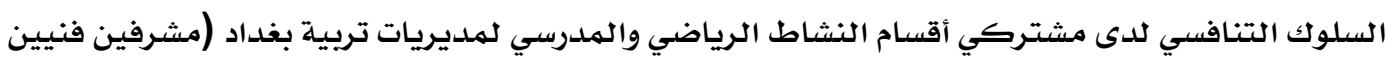

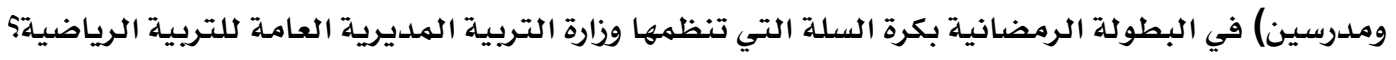




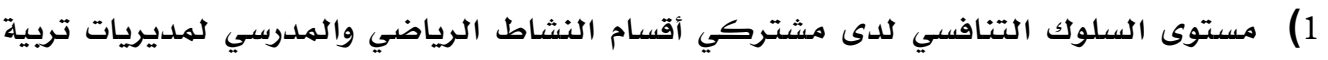

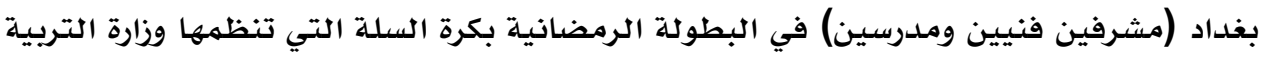
المديرية العامة للتربية الرياضية. 2) الفروق بين المشرفين الفنيين والمدرسين في مستوى السلوك التنافسي.

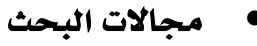 \\ المجال البشري: المشرفين الفنيين والمدرسين التابعين لمديريات تربية بغداد.

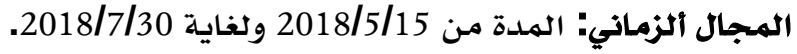 \\ المجال المكاني: الملاعب الرياضية الخاصة بالمنتخبات المالمالهات المشمولة بالبحث.
}

\title{
• مصطلحات البحث
}

البطولة الرمضانية بكرة السلة: هي بطولة سنوية تنظمها وزارة التربية وبإشراف المديرية العامة للتربية

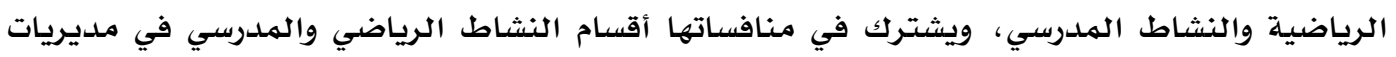
التربية.

\section{الإطار النظري ودراسات سابقة}

السلوكك التنافسي: يسعى الفريق الرياضي من خلال توحيد الجهود إلى تحقيق هدف مشترك، وانكان التهان التعاون

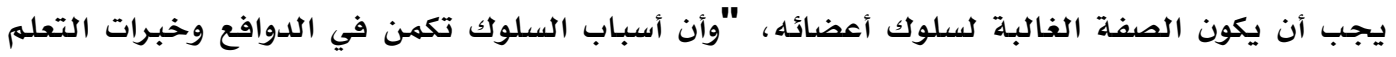

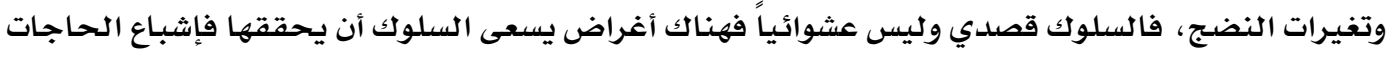

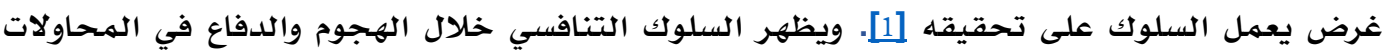

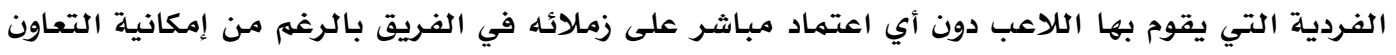

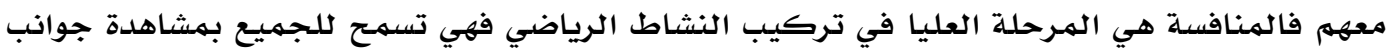

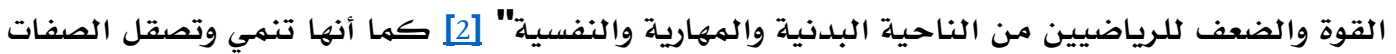

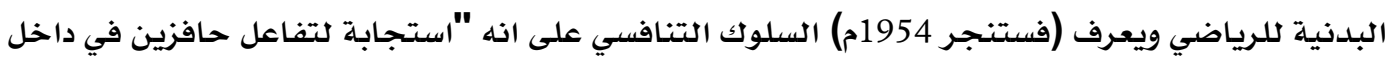
الفرد الحافز الأول صاعدا للأعلى لمواصلة تحقيق قدرات اللاعب والحافز الثاني لمواصلة تقييم قدراته

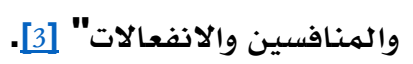

ويعرفه (الشافعي1997م) بأنه "أوجه النشاط الظاهر الذي يمكن ملاحظته بوساطة الغير بالعين المجردة

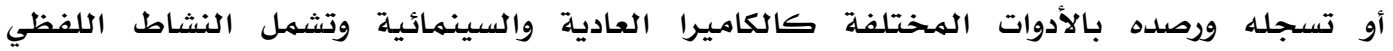

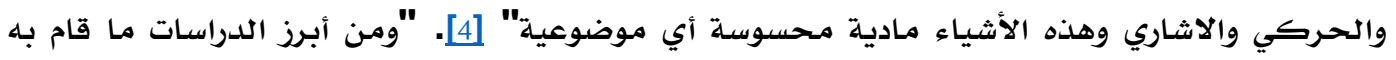

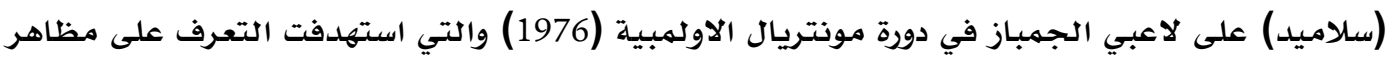

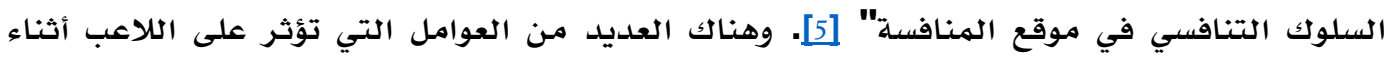

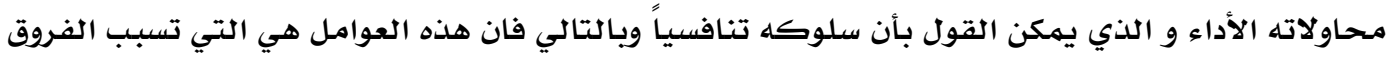

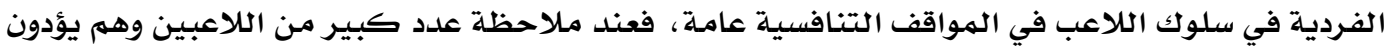

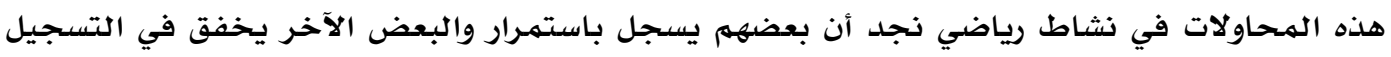
ويعزى ذلك إلى الفروق الفردية بينهم وهي (العمر - الجنس -الثقافة - السمات الشخصية - مكونات

Abbas, N. Radhi, S. (2019). level competitive behavior participants of sports activity and Teacher districts of Baghdad Education Directorate, in basketball championship Ramadan. Journal Port Science Research, 2(2), 305-316. 
موقف المنافسة) والمنافسة هي صراع يتنافس فيه المتنافسون وكل منهم يسعى إلى تحقيق هدف معين

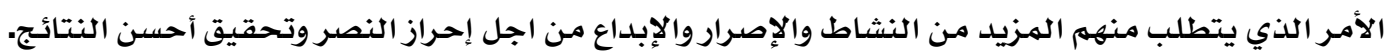

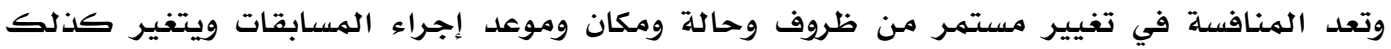

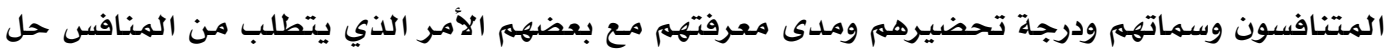

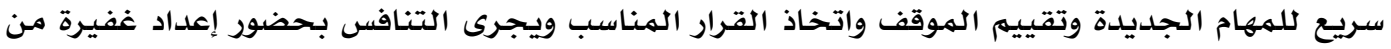

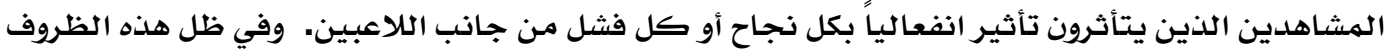

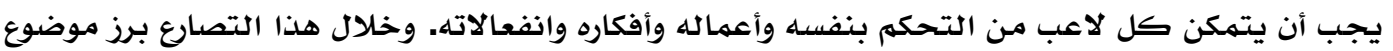

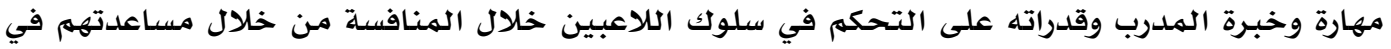

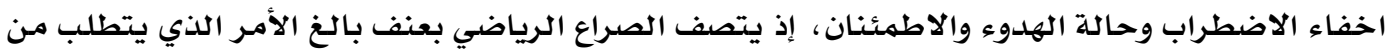
المدرب اليقظة العالية والانتباه والقدرة على تحليل سير المنافسة بسرعة خاطفة [6].

\section{2. منهج البحث وإجراءاته}

ان طبيعة المشكلة وهدف البحث هما اللذان يحددان منهج البحث الملائم وعليه فقد استخدم الباحثان

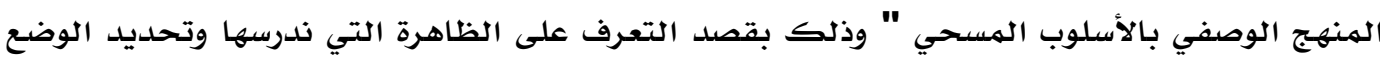

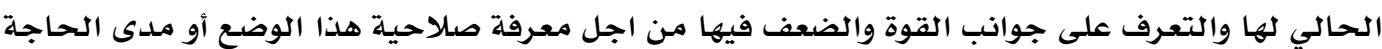

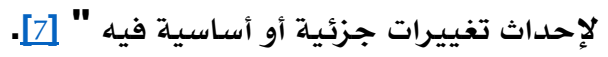

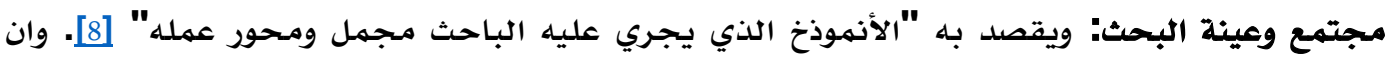
"أهداف البحث والإجراءات التي يستخدمها الباحث تحدد طبيعة العينة التي سيختارها والتي تمثل مجتمع الدراسة " [9].

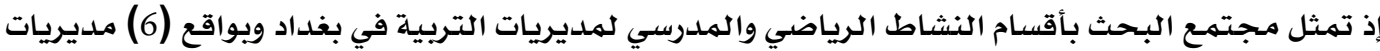

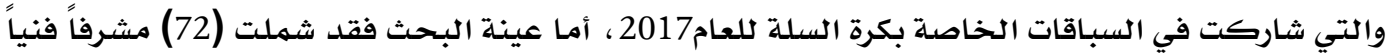

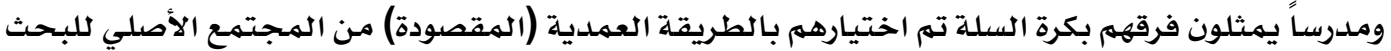

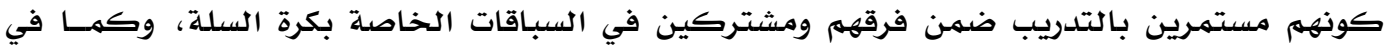

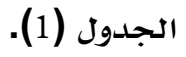

\begin{tabular}{|c|c|c|c|c|}
\hline \multirow[b]{2}{*}{ 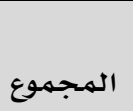 } & \multicolumn{2}{|c|}{ عدد أفراد العينة وفق العنوان الوظيفي } & \multirow[t]{2}{*}{ أسماء المنتخبات } & \multirow[b]{2}{*}{ ت } \\
\hline & مدرس تربية رياضية & مشرف فني & & \\
\hline 12 & 6 & 6 & منتخب تربية الكرج /1 & 1 \\
\hline 12 & 6 & 6 & منتخب تربية الكرج /2 & 2 \\
\hline 12 & 5 & 7 & منتخب تربية الكرج /3 & 3 \\
\hline 12 & 6 & 6 & منتخب تربية الرصافة /1 & 4 \\
\hline 12 & 6 & 6 & منتخب تربية الرصافة /2 & 5 \\
\hline 12 & 6 & 6 & منتخب تربية الرصافة /3 & 6 \\
\hline 72 & 35 & 37 & المجهوع الكلي & \\
\hline
\end{tabular}


الأجهزة والأدوات والوسائل المساعدة في البحث: (مقياس السلوك التنافسي- ملاعب كرة السلة الخاصة

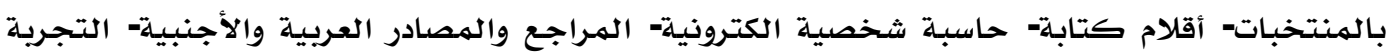
الاستطلاعية- استمارة جمع وتفريغ البيانات).

مقياس (السلوك التنافسي) المستخدم في البحث: استخدم الباحثان مقياس (السلوك التنافسي) الذي قام

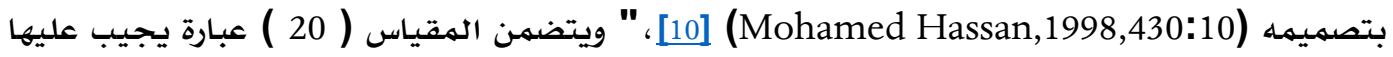

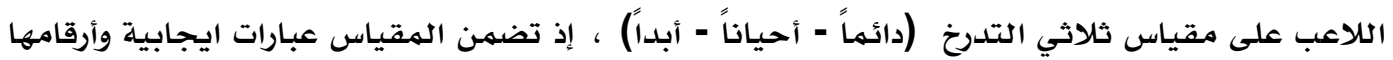

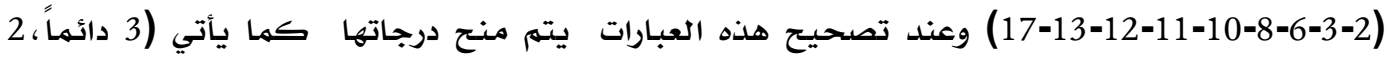

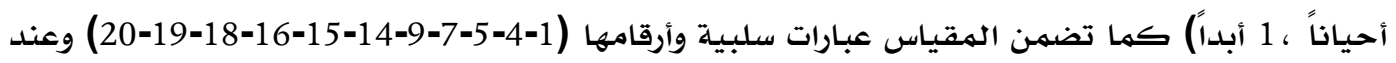

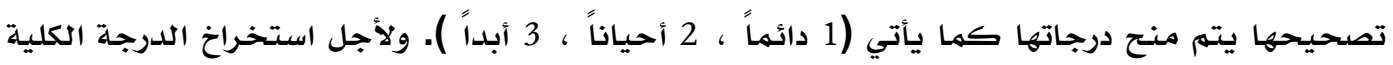

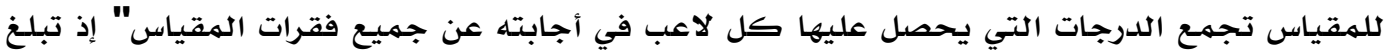

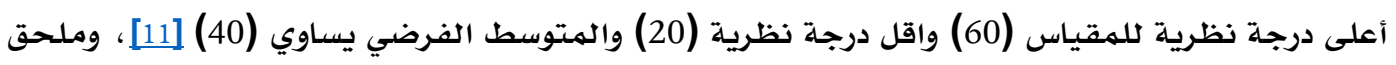
(1) يبين فقرات وبدائل المقياس.

التجرية الاستطلاعية للمقياس: "من أجل التأكد من وضوح تعليمات المقياس وطريقة الإجابة ووضوح

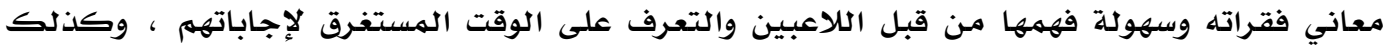

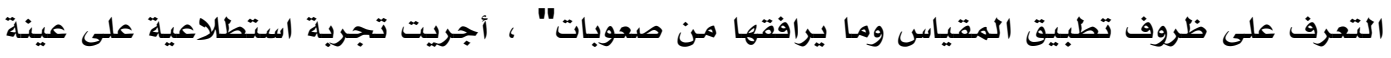

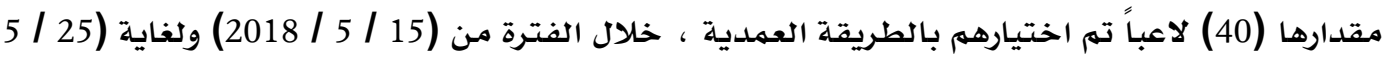

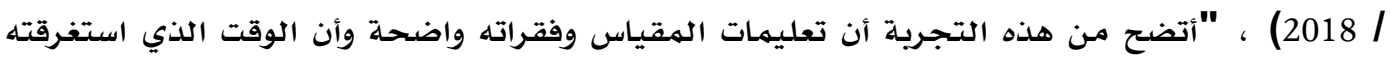

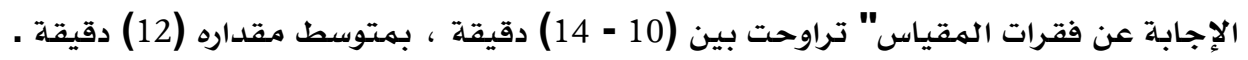

\section{•}

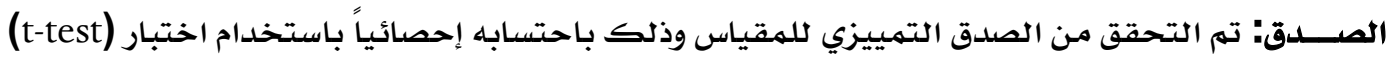

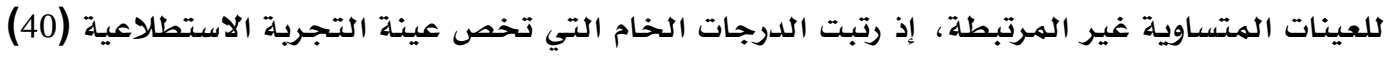

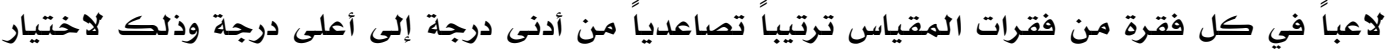

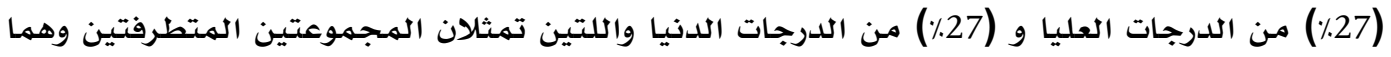

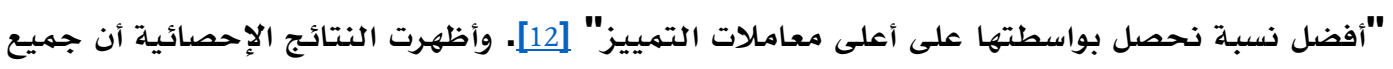

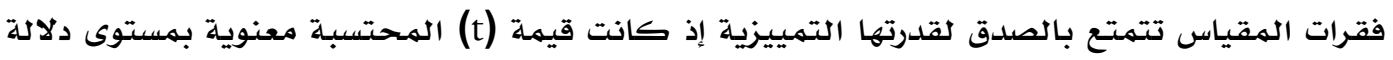

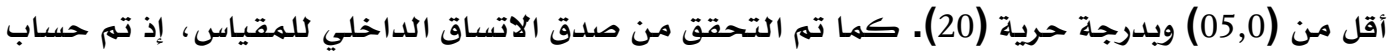

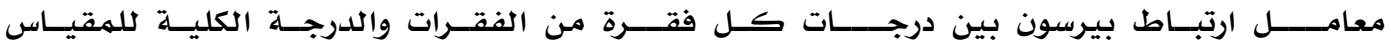
والجدول (2) يوضح ذلك.

\begin{tabular}{|c|c|c|c|}
\hline 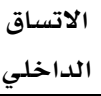 & التمييزية & 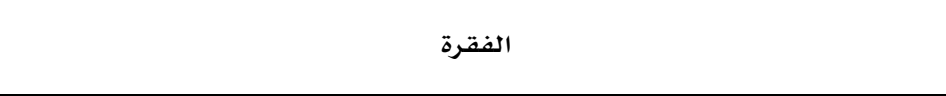 & ت \\
\hline 0,658 & 2,38 & ينخفض مستوى أدائي في المنافسة التي يشاهدها بعض المهمين & 1 \\
\hline 0,570 & 2,35 & عندما ارتكب بعض الأخطاء أثناء المنافسة فأنني لا أجد صعوبة في استعادة تركيز & 2 \\
\hline 0,638 & 2,94 & تزداد ثقتي في نفسي كلما اقترب موعد المنافسة & 3 \\
\hline 0,655 & 3,15 & أعنف نفسي عندما ارتكب بعض الأخطاء أثناء المنافسلة & 4 \\
\hline
\end{tabular}

Abbas, N. Radhi, S. (2019). level competitive behavior participants of sports activity and Teacher districts of Baghdad Education Directorate, in basketball championship Ramadan. Journal Port Science Research, 2(2), 305-316. 
ISSN: 2616-744.

\begin{tabular}{|c|c|c|c|}
\hline 0,619 & 3,88 & عندما ينتقدني مدربي أو أحد زملائي أثناء المنافسة فأنني أجد صعوبة في تركيز انتباهي & 5 \\
\hline 0,607 & 2,13 & تظهر قدراتي العالية بصورة واضحة أثناء المواقف الحساسة في المنافسة & 6 \\
\hline 0,655 & 2,46 & في المنافسات الهامة اشعر بالقلق من عدم قدرتي على الأداء بصورة جيدة & 7 \\
\hline 0,650 & 3,56 & قبل اشتراكي في المنافسة لا احتاخ للمزيد من الوقت لكي استعد نفسياً وذهنياً & 8 \\
\hline 0,641 & 5,60 & ينتابني القلق قبل اشتراكي في منافسة هامة & 9 \\
\hline 0,652 & 2,34 & عندما تسوء الأمور في المنافسة فان ذلك لا يسبب في الارتباك أو القلق & 10 \\
\hline 0,634 & 3,65 & أدائي في المنافسة الرياضية أفضل بكثير من أدائي أثناء التدريب & 11 \\
\hline 0,642 & 2,38 & لا أنفعل أثناء المنافسة عندما اعتقد ان الحكم قد أخطا في بعض قراراته بالنسبة لي أو & 12 \\
\hline 0,656 & 2,35 & بعد انتهاء المنافسة أستطيع أن أتذكر كل ما حدث في المنافسلة & 13 \\
\hline 0,650 & 2,94 & أخشى من احتمال إصابتي أثناء اشتراكي في المنافسة & 14 \\
\hline 0,641 & 3,15 & أحاول تجنب التفكير في المنافسة القادمة لان ذلك يسبب لي المزيد من الضيق & 15 \\
\hline 0,658 & 3,69 & قبل اشتراكي في المنافسة مباشرة اشعر بأنني لا أستطيع تذكر أي شي & 16 \\
\hline 0,634 & 3,66 & مستوى أدائي ثابت في المنافسات وفي حدود قدراتي & 17 \\
\hline 0,648 & 3,56 & بعد انتهاء المنافسة اشعر باني كنت أستطيع الأداء بصورة أفضل & 18 \\
\hline 0,641 & 5,65 & أجد متعة أثناء التدريب بدرجة أكبر منها أثناء المنافسلة & 19 \\
\hline 0,620 & 2,34 & ارتكب بعض الأخطاء في اللحظات الحساسة في المنافسة & 20 \\
\hline
\end{tabular}

$$
\begin{aligned}
& \text { قيمة (13) [13] الجدولية عند درجة حرية (20) ومستوى دلالة (05,0) = } \\
& \text { قيمة (R) [14] الجدولية عند درجة حرية (38) ومستوى دلالة (20,0) }
\end{aligned}
$$

يتبين من الجدول (2) أن قيم (ت) و (ر) المحسوبة كانت معنوية عند مقارنتها بالقيم الجدولية وهذا يدل على صلاحية فقرات المقياس للتطبيق على عينة البحث. ثبات المقياس: تم تقدير ثبات المقياس على أفراد العينة الاستطلاعية باستخدام طريقتي ألفا كرونباج والتجزئة النصفية.

طريقة الفا كرونباج: استخدم الباحثان طريقة ألفا كرونباج لحساب ثبات المقياس، إذ كانت قيمة

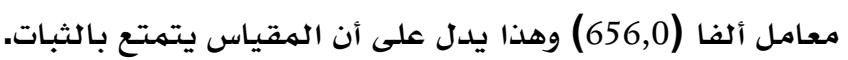

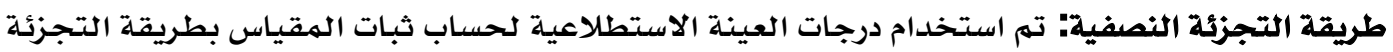

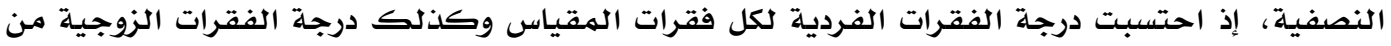
الدرجات، وذلك بحساب معامل الارتباط بين النصفين بعد أن تم التحقق من تكافؤهما ، ثم جرى التعاد تعديل

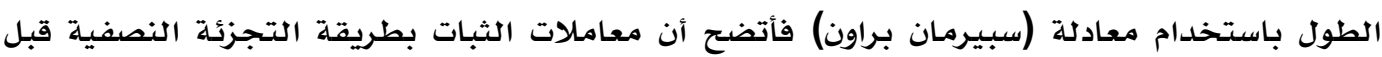

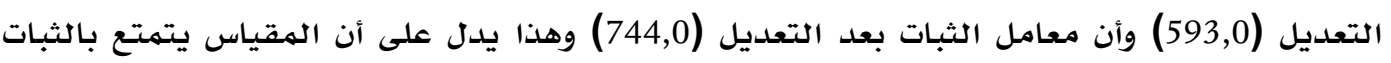

$$
\text { تطمئن الباحث إلى تطبيقه على عينة الدراسة. }
$$

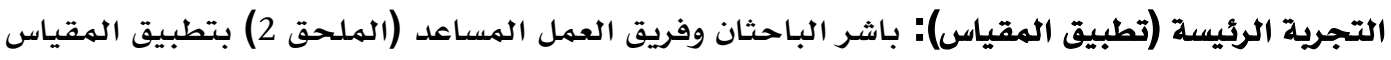

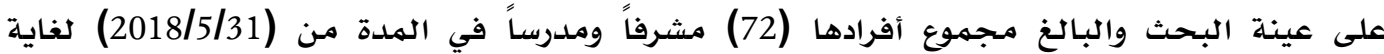


تم استخدام الحقيبة الإحصائية (spss) في إيجاد (التكرارات والنسب المئوية - معامل ارتباط بيرسون

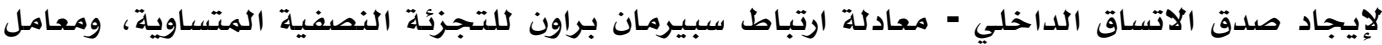
ارتباط ألفا كرونباج لإيجاد معامل ثبات المقياس - اختبار T-TEST الإنسان بران للعينات المستقلة).

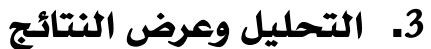

يهدف البحث إلى التعرف على مستوى السلوك التنافسي لدى مشتركي أقسام النشاط الرياضي والمدرسي

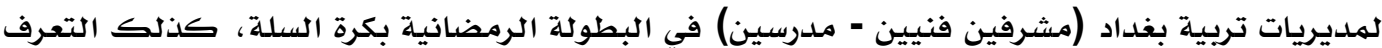
على الفروق بين المشرفين الفنيين والمدرسين في مستوى السلوك التنافسي، وفيما يلي عرض لفرين لنتائج ينص السؤال الأول ملى: ما مستوى السلوك التنافسي لدى مشتركي أقسام النشاط الرياضي والمدرسي

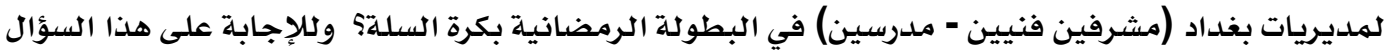
قام الباحثان بإيجاد مجموع الاستجابات والمتوسطات الحسابية والانحراف المعياري والوزن النسبي النيفي والترتيب لكل فقرة من فقرات المقياس والجدول الجان (3) يوضح ذلك. جلدول (3) مجموع الاستجابات والمتوسط الحسابي والانحراف المعياري والوزن النسبي والترتيب لكل فقرة من

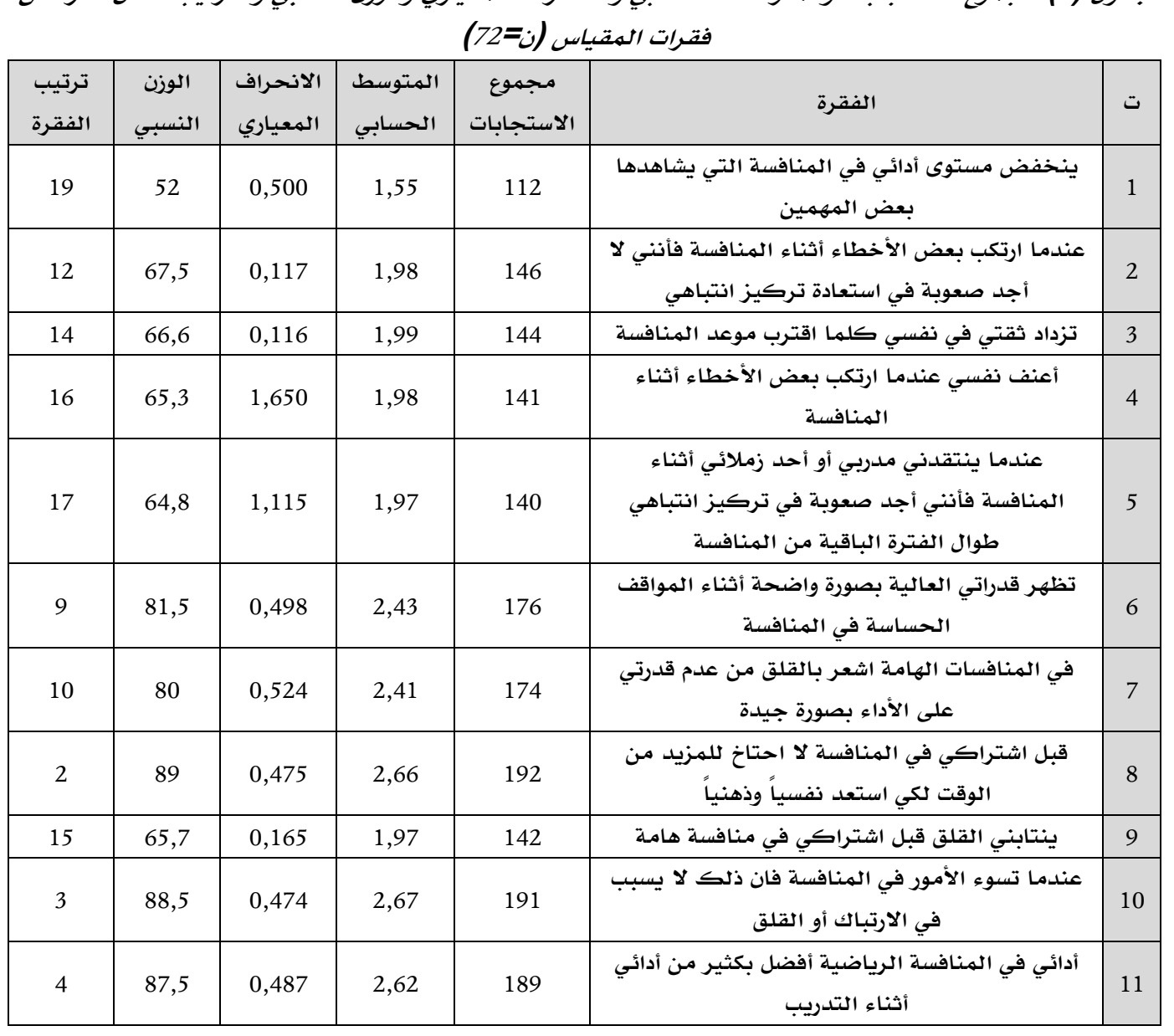

Abbas, N. Radhi, S. (2019). level competitive behavior participants of sports activity and Teacher districts of Baghdad Education Directorate, in basketball championship Ramadan. Journal Port Science Research, 2(2), 305-316. 

j. port. sci. res.
ISSN: $2616-7441$ (Online)
ISSN: $2616-6232$ (Print)
ISSN: $2616-7220$ (USB) INTERNATIONAL IDENTIFIER FOR SERIAL

Journal port Science Research Available online www.jport.co Volume specific: 2 , No:2

\begin{tabular}{|c|c|c|c|c|c|c|}
\hline 1 & 90 & 0,469 & 2,68 & 194 & لا أنفعل أثناء المنافسة عندما اعتقد ان الحكم قد قدراراته بـالنسبـة لي أو لزمـلائي & 12 \\
\hline 5 & 86 & 0,498 & 2,56 & 185 & بعد انتهاء المنافسة أستطيع أن أتذكر كل ما & 13 \\
\hline 6 & 85 & 0,500 & 2,55 & 184 & أخشى من احتمال إصـابتي أثناء اشتراكي في & 14 \\
\hline 13 & 67 & 0,301 & 2,01 & 145 & 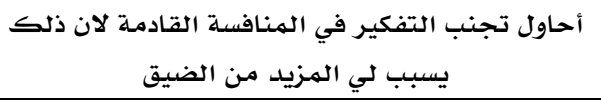 & 15 \\
\hline 11 & 69,5 & 0,278 & 2,08 & 150 & قبل اشتراكي في المنافسة مباشرة اشعر بأنني لا & 16 \\
\hline 7 & 84 & 0,502 & 2,54 & 182 & مستوى أدائي ثابت في المنافسـات وفي حدود قدراتي & 17 \\
\hline 18 & 53 & 0,744 & 1,59 & 115 & بعد انتهاء الهنافسـة اشعر بـاني كنت أستطيع الأداء & 18 \\
\hline 8 & 82 & 0,501 & 2,45 & 177 & أجد متعـة أثناء التدريب بلدرجة أكبر منها أثناء & 19 \\
\hline \multirow[t]{2}{*}{20} & 48 & 0,500 & 1,44 & 104 & ارتكب بعض الأخطاء في اللحظات الحساسـة في & 20 \\
\hline & 73,6 & 3,446 & 44,19 & 3182 & الهـموع & \\
\hline
\end{tabular}

يتضح من الجدول (3) مجموع الاستجابات والمتوسطات الحسابية والانحرافات المعيارية لعينة البحث

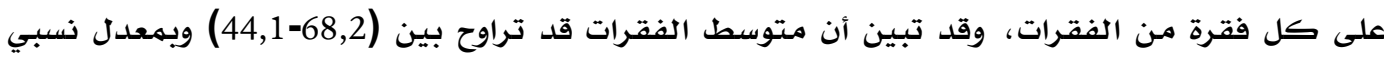

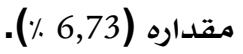

وللتحقق من الهدف الثاني للبحث للتعرف هل يوجد فروق ذات دلالة إحصائية في مستوى السلوك

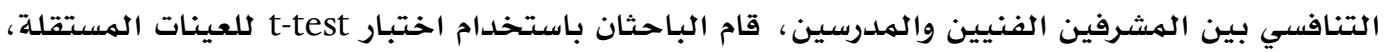
والجدول (4) يوضح ذلك.

جدول (4) الهتوسطات الحسابية والانحرافات الهعيارية وقيمة (ت) للاختبار تعزى للعنوان الوظيفي (ن=72)

\begin{tabular}{|c|c|c|c|c|c|c|}
\hline مستوى الدلالة & قالدلالة & قيمة (ت) & الانحعراف & الحسابي & العدد & العنوان الوظيفي \\
\hline \multirow{2}{*}{ غير دالة } & \multirow{2}{*}{0,073} & \multirow{2}{*}{1,82} & 4,045 & 43,485 & 37 & مشرفين فنيين \\
\hline & & & 2,358 & 44,945 & 35 & مدرسين \\
\hline
\end{tabular}

$$
\text { قيمة (ت) الجدولية عند مستوى دلالة 05,0 = 98,1 (4) }
$$

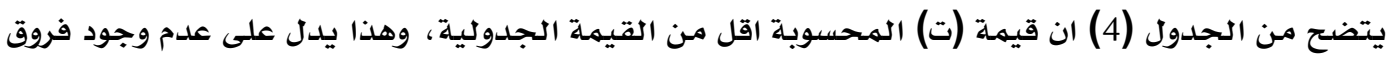
ذات دلالة إحصائية تعزى للعنوان الوظيفي (مشرفين فنيين - مدرسين).

أظهرت النتائج في الجدول (3) إلى ان مستوى السلوك التنافسي لدى مشرفي ومدرسي أقسام النشاط

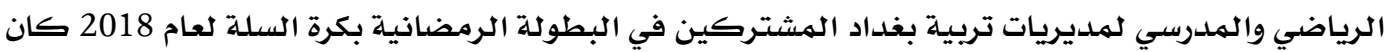




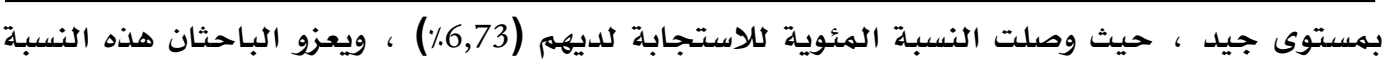

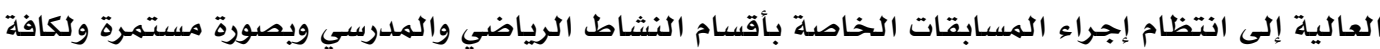

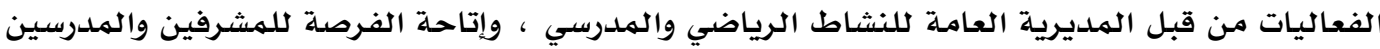

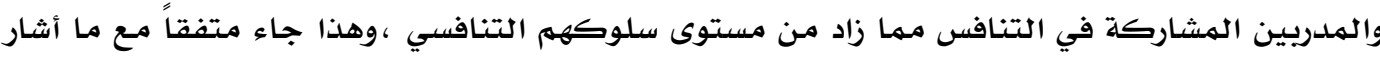

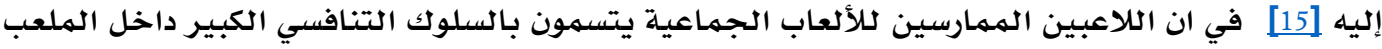

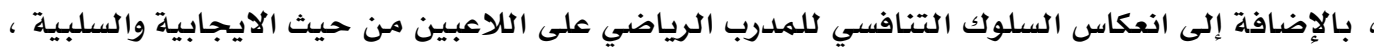
وهذا بدوره ينعكس على الفريق الرياضي بالإيجابية ككل .

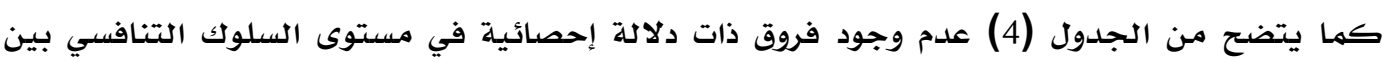

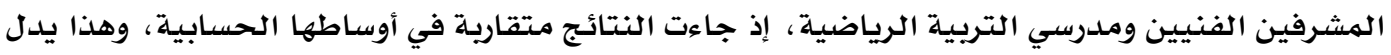

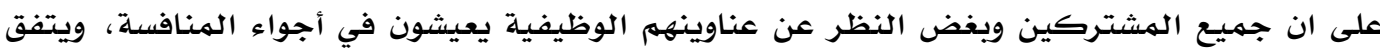

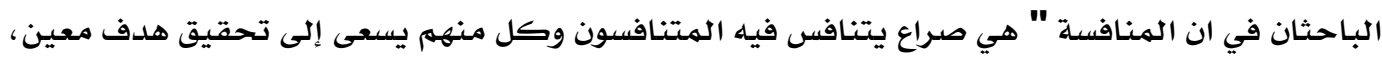
الأمـر الذي يتطلب منهم المزيد من النشاط والإصرار والإبداع من اجل إحراز النصر وتحقيق أحسن النتائج " (Risan Khreibt \& Nahida Rasan, op.cit ,p29).

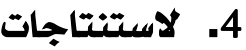
في ضوء النتائج التي أسفرت عنها الدراسة يمكن استنتاخ التالي:

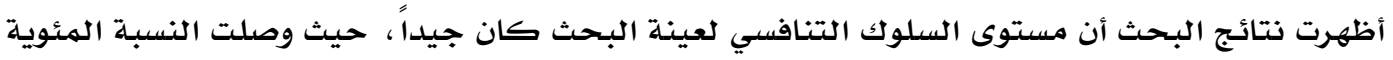

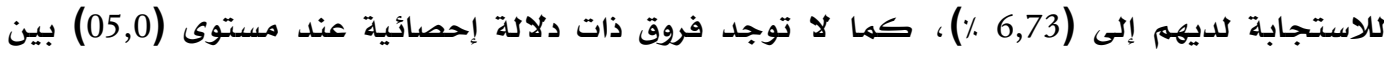

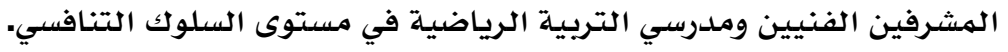

\section{5. والتوصيات}

وعليه فأن الباحثان يوصيان بالتالي: 1) أهمية التركيز على انتظام إجراء المسابقات وبصورة مستمرة ولكافة منتسبي التربية الرياضية

$$
\text { وعدم اقتصارها على فئة اللاعبين. }
$$

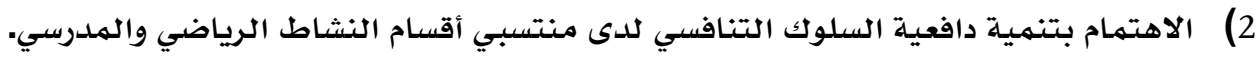

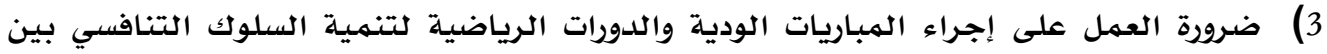

$$
\text { المشتركين. }
$$

4) إمكانية تحديد مستويات معيارية للسلوك التنافسي لدى مشتركي أقسام النشاط الرياضي والمدرسي لمديريات تربية بغداد في البطولة الرمضانية بكرة السلة.

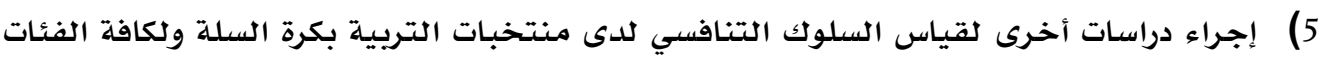
بنين وينات. 
[1] Adas, A. R., Qatami, N. (2002). مبادئ علم النفس >. Principles of Psychology, Jordan, Dar Al fikr for printing and publishing, p211. http://www.daralfiker.com/node/6858

[2] Fawzy, A. A., Badr al-Din, T. M. (2001). سيكولوجية الفريق الرياضي>> Cairo: Dar Al fikr Al Arabi , p83. http://www.philadelphia.edu.jo/newlibrary/2014-11-24-13-12-11/538-

2014-11-23-08-04-46/80120-55614

[3] Sharp, L. A., Hodge, K., \& Danish, S. (2014). Sport psychology consulting at elite sport competitions. Sport, Exercise, and Performance Psychology, 3(2), 75-88. https://doi.org/10.1037/spy0000011

[4] Shafei, H. A. (2000). المسؤولية في المنافسات الرياضية الدولية والمحلية >. Cairo, Dar Al Maarif, p107. http://dar.bibalex.org/webpages/mainpage.jsf?PID=DAF-Job:53666

[5] Chamoun, M. (2001). > علم النفس الرياضي والقياس النفسي> markaz alkitab for Publishing. https://www.neelwafurat.com/itempage.aspx?id=egb44527-5044548\&search=books

[6] Majid, R. K. (1988). علم النفس في التدريب و السسابقات الرياضية الحديثة> Basra: University of Basra. http://www.iraqnla-iq.com/opac/fullrecr.php?nid=46689\&hl=ara

[7] Adas, R. A., Eubaydat, T., Abdel Haq, K. (2016). البحث العلمي مفهومه أدواته أساليبه> >. Dar Al fikr pu blishing and distribution, p201. https://www.daralfiker.com/node/6497

[8] Mahjoub, W. (2004). اصول البحث العلمي و مناهجه> > Amman: Dar Al Hikma for printing \&publishing, p181. https://pmb.univsaida.dz/budspopac/index.php?|vl=notice display\&id=166

[9] Mahmoud Ali, R., Hussein Mohamed, A., Ahmed Hazem, A. (2008). Constructing A., the Work Satisfaction Measures of the Teaching Staff of the College Departments of Physical Education in the University of Mosul. College of Basic Education Researches Journal, 1(7). https://www.iasj.net/iasj?func=article\&ald=7381

[10] Hassan Allawi, M. (1988) > موسوعة الاختبار ات النفسية للرياضيين. Cairo: The book Center for publishing, p430. https://drive.google.com/file/d/OB9x5L29xpeaaTUpJM25vRONiMIE/view

[11] Awad, A. (1988). القياس النفسي بين النظرية و التطبيق> > Egypt: Publisher maharat alnajahi, Issuance dar almaerifat aljamieia. https://www.jamaa.net/books. library/?id=1549

[12] Ouda, A. (2005). القياس و التقويم: في العملية التدريسية> Jordon: Dar Al Amal publishing and Distribution, p286. https://libserver.bethlehem.edu/webopac/records/1/87296.aspx

[13] Samoum, F. A. (2007). مبادئ الطرق الاحصائية في التربية الرياضية > baghdada:mtabeat almuhaymin. http://www.iraqnla-iq.com/opac/fullrecr.php?nid=241520\&hl=ara

[14] Al Shayeb, A. Q. (2009). أسس البحث التربوي> >. Amman: Dar Wael Publishing and Distribution. http://search.shamaa.org/FullRecord?ID=25950

عباس، نصير خضير. راضي، سعد خميس. (2019). مستوى السلوك التنافسي للمشاركين في النشاط الرياضي والمدرسين

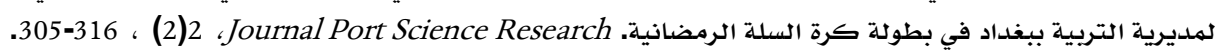


[15] Danielson, R. R., Zelhart, P. F., \& Drake, C. J. (1975). Multidimensional scaling and factor analysis of coaching behavior as perceived by high school hockey players. Research Quarterly of the American Alliance for Health, Physical Education and Recreation, 46(3), 323-334. https:// doi.org/10.1080/10671315.1975.10616683

Abbas, N. Radhi, S. (2019). level competitive behavior participants of sports activity and Teacher districts of Baghdad Education Directorate, in basketball championship Ramadan. Journal Port Science Research, 2(2), 305-316. 
الملحق (1)

(مقياس السلوك التنافسي المستخدم في الدراسة)

\begin{tabular}{|c|c|c|c|c|}
\hline أبداً & أحياناً & دائماً & الفقرات & ت \\
\hline & & & ينخفض مستوى أدائي في المنافسة التي يشاهدها بعض المهمين & 1 \\
\hline & & & عندما ارتكب بعض الأخطاء أثناء المنافسة فأنني لا أجد صعوبة في استعادة & 2 \\
\hline & & & تزداد ثقتي في نفسي كلما اقترب موعد المنافسة & 3 \\
\hline & & & أعنف نفسي عندما ارتكب بعض الأخطاء أثناء المنافسة & 4 \\
\hline & & & 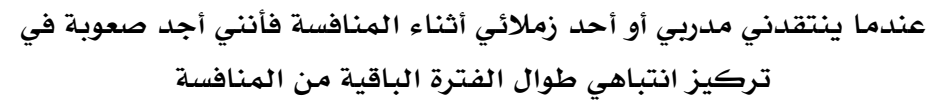 & 5 \\
\hline & & & تظهر قدراتي العالية بصورة واضحة أثناء المواقف الحساسة في المنافسة & 6 \\
\hline & & & في المنافسات الهامة اشعر بالقلق من عدم قدرتي على الأداء بصورة جيدة & 7 \\
\hline & & & قبل اشتراكي في المنافسة لا احتاخ للمزيد من الوقت لكي استعد نفسياً & 8 \\
\hline & & & ينتابني القلق قبل اشتراكي في منافسة هامة & 9 \\
\hline & & & عندما تسوء الأمور في المنافسة فان ذلك لا يسبب في الارتباك أو القلق & 10 \\
\hline & & & أدائي في المنافسة الرياضية أفضل بكثير من أدائي أثناء التدريب & 11 \\
\hline & & & لا أنفعل أثناء المنافسة عندما اعتقد ان الحكم قد أخطا في بعض قراراته & 12 \\
\hline & & & بعد انتهاء المنافسة أستطيع أن أتذكر كل مـا حدث في المنافسة & 13 \\
\hline & & & أخشى من احتمال إصابتي أثناء اشتراكي في المنافسة & 14 \\
\hline & & & أحاول تجنب التفكير في المنافسة القادمة لان ذلك يسبب لي المزيد من & 15 \\
\hline & & & قبل اشتراكي في المنافسة مباشرة اشعر بأنني لا أستطيع تذكر أي شي & 16 \\
\hline & & & مستوى أدائي ثابت في المنافسات وفي حدود قدراتي & 17 \\
\hline & & & بعد انتهاء المنافسة اشعر باني كنت أستطيع الأداء بصورة أفضل & 18 \\
\hline & & & أجد متعة أثناء التدريب بدرجة أكبر منها أثناء المنافسة & 19 \\
\hline & & & ارتكب بعض الأخطاء في اللحظات الحساسة في المنافسة & 20 \\
\hline
\end{tabular}

الملحق (2)

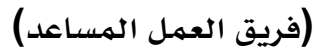

\begin{tabular}{|c|c|c|c|}
\hline مشرف فني - قسم النشاط الرياضي والمدرسي - تربية الكرج الثانية & احمد عبد الله حسين & مי د & 1 \\
\hline مدرس - تربية الكرج الثالثة & حيدر عبد الأمير حبيب & 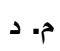 & 3 \\
\hline مدرس - تربية الكرج الثانية & أياد عبد اللطيف علي & م. م د & 4 \\
\hline
\end{tabular}

